\title{
Caminos y derivas para otra investigación educativa y social
}

\author{
Jesús Javier Moreno Parra*
}

Recibido: 3 de septiembre de 2020 Aceptado: 4 de septiembre de 2020 Publicado: 30 de septiembre de 2020

To cite this article: Moreno, J. (2020). Reseña de Sancho, J. Ma , Hernández, F., Montero, L., de Pablos, J., Rivas, I. y Ocaña, A. (Coords.) (2020). Caminos y derivas para otra investigación educativa y social. Márgenes, Revista de Educación de la Universidad de Málaga, 1 (3), 393-395

DOI: https://dx.10.24310/mgnmar.v1i3.10156

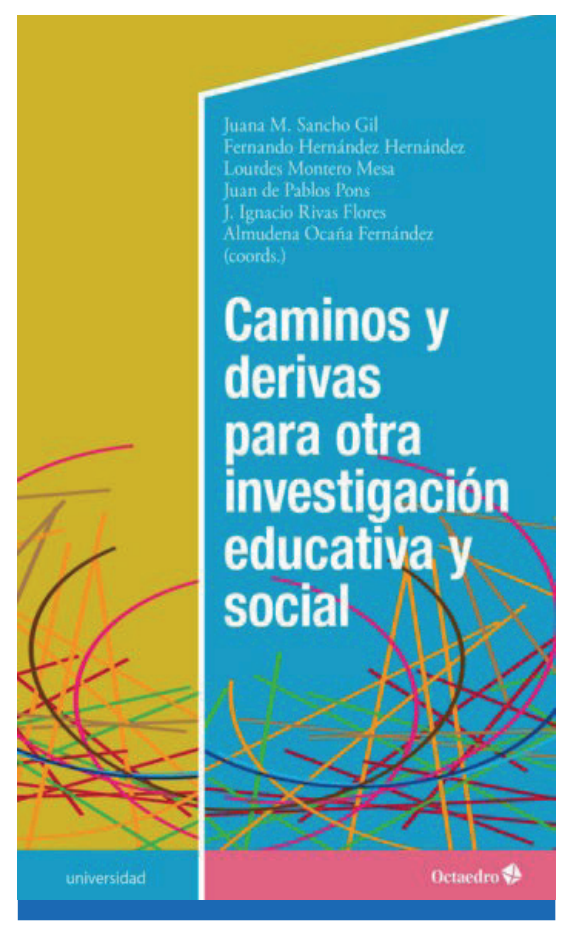

Caminos y derivas para otra investigación educativa y social. Moreno, J. (2020). Reseña de Sancho, J. Ma , Hernández, F., Montero, L., de Pablos, J., Rivas, I. y Ocaña, A. (Coords.) (2020). Caminos y derivas para otra investigación educativa y social. (2020). Barcelona. Octaedro, pp. 315. ISBN: 978-84-18083-69-3

\section{RESUMEN}

En "Caminos y derivas para otra investigación educativa y social”, encontramos el trabajo de un grupo de investigadores e investigadoras, pertenecientes a la red de excelencia REUNI+D, en relación a la investigación educativa y social. Abarca y profundiza en cuestiones epistemológicas, ontológicas, metodológicas y éticas, trascendiendo el debate "cuantitativo vs cualitativo", poniendo en el centro la necesidad de atender a otras formas de entender la investigación. Formas de investigar que, en parte, podrían ser entendidas como posiciones de resistencia. El libro pone en el centro del debate la necesidad de repensar la tendencia, los caminos y las derivas que ha tomado la investigación educativa. Nos invita a repensar el sentido de la investigación, de sus fundamentos y prácticas, que en la búsqueda de reconocimiento, de un lugar dentro de instituciones conservadoras, ha ido cediendo espacio a debates estériles, cuestiones formales y protocolarias, desplazando en parte el objetivo de la transformación social. Es por tanto un libro con un alto valor para la comunidad investigadora, tanto para aquellos investigadores que tienen una extensa trayectoria, como para aquellos que empezamos.

Palabras clave: investigación; ontoespistemología; metodologías; responsabilidad en la investigación

En esta obra, "Caminos y derivas para otra investigación educativa y social", podemos encontrar el trabajo de un grupo de investigadoras e investigadores que nos invita a pensar juntos la complejidad de la investigación educativa, atendiendo a las distintas posiciones y a la diversidad que entraña ésta en nuestros días, así como su sentido desde posiciones críticas. 
Partiendo de una posición marcadamente sociocrítica, la red de excelencia REUNI+D -Red Universitaria de Investigación e innovación Educativa-, plantea la necesidad de revisar esos caminos y derivas que ha tomado la investigación educativa, que buscando el reconocimiento o incluso la supervivencia dentro de instituciones conservadoras y hegemónicas, ha ido cayendo en debates estériles preocupados por cuestiones formales, programáticas y protocolarias, dejando en un segundo plano el valor de la transformación social. Como consecuencia, la instrumentalización y la estandarización de la investigación educativa y social, ante la sombra de modelos hegemónicos de corte positivista, está permitiendo un mayor control político y una mejor adecuación a un sistema regido por el mercado. En estas lógicas técnico-procedimentales, positivistas, de mercado... no hay espacio para cuestiones de orden ontológico, metodológico, epistemológico y ético. El libro se presenta como un diálogo actualizado sobre distintos debates y desafíos que se han ido sucediendo en las últimas décadas en torno a la investigación educativa y social desde otros fundamentos, permitiéndonos repensar, junto a este grupo de investigadores e investigadoras, el sentido y valor de investigar en educación, así como en cualquier ámbito social. Por ello se presta especial atención a esas cuestiones de orden ontológico, epistemológico, metodológico y ético, siendo estas las dimensiones que dan forma al libro.

Tras una presentación y una introducción que nos plantean el sentido propio de la obra, nos encontramos tres grandes bloques. El primer bloque, "Ontoepistemologías emergentes: De aquello que no se puede separar”, consta de siete capítulos donde se plantean distintos planteamientos que permiten conocer y reflexionar acerca de los cambios que se están dando en las diferentes maneras de entender lo social, así como al sujeto y la propia realidad. Como alternativa a una epistemología hegemónica de corte positivista, neoliberal y patriarcal, en este bloque se plantean transformaciones que se están dando en el conocimiento educativo y social. Se trata de planteamientos contrahegemónicos que podríamos nombrarlos como ontológicos, posmaterialistas, poshumanistas, investigación poscualitativa, perspectiva decolonial, el giro feminista e inclusivo. Desde estas posiciones se cuestionan aquellos planteamientos que se ofrecían como transformadores, pero que formando parte de distintas instituciones formales y tradicionales, han ido cayendo en una ortodoxia inmovilista, perdiendo así el sentido inicial. Desde estos planteamientos alternativos se nos invita a pensar y construir a partir de otros fundamentos para una investigación más compleja, comprometida socialmente, que recupere su sentido transformador, poniendo en el centro cuestiones fundamentales y de gran importancia en la actualidad.

Encontramos un segundo bloque llamado "Perspectivas metodológicas", donde se muestran distintas y diversas maneras de investigar, en coherencia con el mostrado en el primer bloque. Se revisan planteamientos que ya tienen un amplio recorrido en la investigación educativa y social, así como otros emergentes. Se plantean otras formas de entender las relaciones dentro de la investigación, distintas estrategias que permiten otro tipo de participación de los sujeto, otras maneras de acercarnos la investigación. Planteamientos que nos permiten establecer formas de participación horizontales que, junto a la apertura necesaria hacia procesos emergentes y motivado desde los intereses de los propios participantes, promueven la democratización del proceso de investigación.

En esta ocasión el bloque lo componen ocho capítulos que muestran diversos planteamientos y posibilidades que ofrecen desde propuestas estructuradas, como la perspectiva socio-cultural 
y la investigación basada en diseño; hasta otras propuestas que ponen en el centro a los sujetos y apuestan por diseños emergentes, como la investigación participativa o colaborativa, la investigación narrativa y biográfica, o la investigación basada en las artes. Además se presentan nuevas propuestas que configuran los ámbitos de lo educativo y lo social, como puede ser la etnografía en la era de lo (pos)digital, la investigación en tecnologías educativas o el compromiso de la investigación respecto a la formación de la ciudadanía en un tiempo marcado por la complejidad y la diversidad sociopolítica.

Para concluir encontramos un tercer bloque, "Ética, evaluación, divulgación y responsabilidad de la investigación”, en el que se muestra una concepción de la investigación que se entiende como parte de un proceso social, político y moral. El investigador de esta manera se debe a su compromiso ético-político, contribuyendo de esta manera al cambio, en pos de la transformación social hacia una sociedad más justa, solidaria, equitativa y libre. Por tanto, los autores y autoras nos invitan a repensar el papel de la investigación en este sentido, desde modelos sociales que están configurando y transformando la realidad educativa y social. Del mismo modo, nos permite reflexionar acerca de las estrategias de divulgación, evaluación y valoración, en los que se ve inmerso el investigador.

Por todo ello, estamos ante una obra colectiva que nos permite cambiar la mirada, y cuestionar prácticas y planteamientos cotidianos y naturalizados dentro del ámbito de la investigación educativa y social que, lejos de promover la transformación, pueden estar perpetuando el inmovilismo. Es por tanto una obra interesante para cualquier investigador o investigadora, pero se hace casi esencial para aquellos que nos estamos iniciando en esta labor. 